- The use of family case study programmes has been limited in dental undergraduate training.

- This study describes a Family Study carried out at Cardiff aimed at providing a range of benefits to the dental students who took part.

- The Family Study at Cardiff represents an innovative method of delivering and supporting behavioural sciences teaching in dental education.

\title{
Introducing a family case study to the dental undergraduate curriculum
}

\author{
K. F. Stewart, ${ }^{1}$ M. Z. Morgan ${ }^{2}$ and E. T. Treasure ${ }^{3}$
}

The 'Family Study' was introduced at Cardiff Dental School in the 2001/2 session. Students are paired with local families who they visit over three years to collect information about family structure, childhood development and health behaviours, which forms the basis of a major project in year 4. In this paper, data gained from the first cohort of students to complete the study are reviewed, together with a practical evaluation of the programme's delivery and teaching gains.

\section{INTRODUCTION}

The data show that students generally gain:

- A broader understanding of family structures

- A conceptualisation of the fluidity of family life

- A sense of the intra-family power relationships away from clinical settings

- Practical interviewing skills.

Challenges implementing this teaching method include conveying the direct applicability of the projects, especially at the outset, and organisational issues of recruitment and retention of participating families.

The Family Study represents an innovative method of delivering and supporting behavioural sciences teaching, offering opportunities to apply findings across a range of subject areas (including

${ }^{1 *-3}$ Cardiff University, Dental Health and Biological Sciences, Heath Park, Cardiff CF14 4XY

${ }^{*}$ Correspondence to: Dr Kate Stewart

Email: stewartkf@cf.ac.uk

\section{Refereed Paper}

Accepted 3 August 2006

DOI: $10.1038 /$ bdj.2007.77

${ }^{\circledR}$ British Dental Journal 2007; 202: 151-155 communications skills, clinical practice, public health, child development, and research methods). It roots behavioural sciences teaching in applied environments, away from clinical settings, and helps support a more integrated approach to learning and patient care.

Family Case Study and outreach teaching The first five years ${ }^{1}$ has encouraged diversity in teaching methods in dental education, in the same way that Tomorrow's Doctors $^{2}$ was a crucible for more learner focussed approaches to medical undergraduate training. Family case study programmes have become commonplace in undergraduate medical curricula, particularly since the recommendations of the General Medical Council in Tomorrow's Doctors, ${ }^{2}$ which directed educators to the value of learner centred, problem orientated approaches. ${ }^{3}$ Accounts of these family case study programmes have detailed how they have contributed to student learning, and the benefits are varied. Forster et al. ${ }^{4}$ describe the Family Study at the University of Newcastle-upon-Tyne Medical School as the 'cornerstone' to students' practical experience with patients. In Cardiff, where the undergraduate medical curriculum has included a family case study for over 15 years, the programme's outcomes include the development of professional skills such as communications, and skills in self- directed learning. ${ }^{5}$ Such programmes also allow students first hand experience of medical, psychological and organisational issues that relate to health care, provide insights into home circumstances that may affect patient management, and give students a knowledge of family priorities that is important in understanding their health behaviours. ${ }^{6}$ There is also evidence that increased community based experience during training (of which family case studies are one element) can significantly alter career preference, encouraging community based careers among those who have had increased experience of this mode of learning. ${ }^{7}$

In dental undergraduate education, outreach teaching as a whole is increasingly common. Primarily, outreach programmes provide community clinical teaching settings for students, but also include programmes where community based attachments with organisations such as CDS clinics, general practices, school and care homes enhance students' understanding of a wider range of social 


\begin{tabular}{|c|c|}
\hline Year 1 & $\begin{array}{l}\text { Students will: } \\
\text { - understand the principles of questionnaire design and eliciting information from } \\
\text { structured data collection tools } \\
\text { - have organised and conducted interviews with structured questionnaires } \\
\text { - established an initial relationship with placement family in the first visit }\end{array}$ \\
\hline Year 2 & $\begin{array}{l}\text { Students will: } \\
\text { - have reflected on the data collected in year } 1 \text { and its relationship to comparable local and } \\
\text { national data } \\
\text { - have re-established contact with families for the second visit, or established contact with } \\
\text { a replacement family } \\
\text { - understand the social and physical growth and change of the placement family and } \\
\text { named child } \\
\text { - have a more critical understanding of the dynamics of family life }\end{array}$ \\
\hline Year 3 & $\begin{array}{l}\text { Students will: } \\
\text { - have re-established contact with families for the third visit, or established contact with a } \\
\text { replacement family } \\
\text { - understand the principles of semi-structured interviewing } \\
\text { - have constructed open ended questions for inclusion in the final visit questionnaire, and } \\
\text { conducted the interview with these }\end{array}$ \\
\hline Year 4 & $\begin{array}{l}\text { Students will have completed a 3,000 word report including: } \\
\text { - a retrospective case study of the family visited, or case study comparison of families } \\
\text { visited for those students whose original families had to be replaced } \\
\text { - an analysis of the Family Study whole dataset } \\
\text { - a methodological critique of data collection methods used } \\
\text { - a reflective account of the learning experience associated with the Family Study }\end{array}$ \\
\hline
\end{tabular}

and organisational issues related to health care in general and oral health care specifically. ${ }^{8}$ Community based learning also strengthens students' confidence in patient management and communication. ${ }^{9}$ Arguably driven by the practicalities of increased numbers as much as any pedagogical shift, dental schools are moving away from being the 'total learning environment' for undergraduate and postgraduate students. ${ }^{10}$ Outreach teaching in the form of family case studies, as used in undergraduate medical training, has not so far been widely adopted in undergraduate dental training, although a number are running. ${ }^{8}$ The 'Family Study' was introduced at Cardiff Dental School in the 2001/2 academic session as part of the introduction of a completely revised curriculum. In this paper, the data gained from the first cohort of students to complete the study are reviewed, together with a practical evaluation of the programme in terms of its delivery and teaching gains.

\section{The Family Study}

The Family Study is part of the 'Dentistry in the Wider Community' curriculum theme (which includes dental public health, behavioural sciences, and law and ethics), and is organised and delivered by the behavioural sciences teaching staff within the school. The on how to be alert to any signs that parents may be unwilling to continue their participation, and replacement families are available if initial families withdraw.

The Family Study design consists of four stages each supported by class based teaching to introduce the principles and background to the content and structure of interviews, and followed by feedback of the results collected by the year group as a whole. The mix of theoretical and practical components, and the integration of the visits to other curriculum areas (such as paediatric dentistry and orthodontics in this instance), are an important feature of family outreach programmes. ${ }^{4}$ In year 1 students are given practical and class-based interview training. This is combined with their introductory class on taking a patient history to reinforce the similarities in using structured instruments to elicit information for a specific purpose: the key aim of both research interviewing and history taking. They have the opportunity to administer a practice questionnaire, and are introduced to the questionnaires they will use on their first family visit. Recruitment permitting, students make their first family visit to administer a highly structured questionnaire in their second term. Students are not involved in the design of questionnaires, but a critique of the questionnaires forms part of the final project. Topics covered in this visit include household size and structure, childcare arrangements, social networks, immunisation, healthcare and dental attendance. Following their first visit students are required to submit a short 'first visit report' reflecting their experiences and observations of the visit. This is used to monitor learning issues related to the visits, and is a helpful account for students' project work in year 4. In year 2 students make their second family visit, to administer a slightly less structured questionnaire. This charts any changes in household composition since the previous visit, and includes questions about language and play as well as health and child care topics touched on in year 1 . In year 3 the final family visit preparation introduces principles of semi-structured interview techniques and students develop questions for their final visit. Students at this stage of their course have gained more expertise and confidence dealing with the public, and 
have in many cases established a good rapport with the families they are visiting. Allowing them to develop their own questions at this final visit also allows them to focus on areas of interest that they identify, or on topics that may be peculiar to the placement family they are visiting. In year 3, the Family Study questionnaires have now also been introduced in a practical task in the statistics course, providing a further link to other curriculum areas. In year 4 students complete a final written project of 3,000 words incorporating elements of case study, data analysis, methodological critique and reflective learning accounts. This final report forms part of their summative assessment and is carried forward to their final degree result.

Students submit reflective learning notes after family visits which highlight the practicalities, limitations and benefits of introducing social science teaching issues to dental undergraduates in this way. From these, key issues relating to the introduction of the Family Study can be identified. These themes are presented below, using illustrative extracts from students' reports where appropriate. Student feedback has thus far been monitored through the first visit written report and final project reflective accounts. Using this type of unstructured open-ended feedback has been invaluable for the developmental aspects of introducing this new curriculum component, helping a robust, reflective approach to the delivery of the project. The 'gains' identified in this paper are generated from, and supported by, the qualitative data collected from this process. In future, data collected this way will be used to develop a more conventional structured, quantitative appraisal of teaching.

\section{STUDENTS GAIN:}

\section{A broader understanding of family}

structures and family life

Families are recruited from the Cardiff area, through health visitors, family doctors and childcare groups. Approximately one in 10 of the families are single parent households, one in 10 are workless households (ie households with at least one person of working age containing no adults in employment), and one in 20 live with extended family members. Each of the families has at least one child under the age of five years at the start of the study, and these children range in age from a few weeks to four years at the start of the study, although most are under one year. As has been noted by evaluations of similar undergraduate programmes in medicine, students are often exposed to socio-cultural situations quite different to those they have experienced through their own. ${ }^{4}$ In any case, students are thinking about family issues in the nonclinical environment:

'We saw $M$ in his natural environment without anything being put on for show.'

This process not only allows but encourages students to take note of activities and features not normally otherwise ever considered relevant in their training:

'She'd forgotten we were coming round and was in an apron cooking cakes.'

As the extract above illustrates, while what they note might not always necessarily seem directly relevant to the dental profession, the project's value lies in the development of this intellectual skill of thinking more broadly.

\section{A sense of the intra-family relationships} away from the clinical setting

Approximately one third of the children in the study have formal childcare arrangements outside the home, with most children being cared for exclusively by their parents. Often students visit families when both parents are present, and are able to observe families together in their own homes.

'Both of the parents were at home when we went to conduct the interview, on a weekday afternoon ... I was slightly surprised to see that considering that both the parents work.'

'Both parents were present and the father showed a great interest in $R$, answering some of the questions and on occasion they would confer with each other.'

' $L$ remained close to her mother and held her hand for reassurance ... she did not crawl towards us but was happy to sit in close proximity to us.'

Such experiences and observations encourage the students to consider differential parental roles within the home: who knows what and, how decisions are made, how children behave with their parents and what each parent's priorities are. A realisation of these dynamics in the home develops students' skills in developing appropriate treatment plans and behavioural advice.

Practical interviewing skills

As mentioned previously, before students make their first family visit, they are given basic interview training, taught in conjunction with instruction on taking a history. This introduces theories relating to asking questions with a purpose, which are then supported and developed through the process of arranging, administering, recording and critically reviewing the family study interviews. This involvement in collecting data with an interviewer administered questionnaire gives students an understanding of practical research issues, as well as relating to developing patient management skills, as mentioned previously. Some will go on to administer surveys of their own as part of their final year project, others will be involved in data collection as their career progresses, and as lifelong learners all will be consumers of research for whom an understanding of data collection is an important asset.

'She responded really well to our questions and was very forthcoming with her answers.'

'When I phoned the family to arrange the meeting the mother seemed very accommodating and pleasant, and made me less nervous.'

Clearly the project develops relevant academic and clinical skills, but also crucially supports students' confidence in these interpersonal skills.

\section{CHALLENGES IMPLEMENTING THIS TEACHING METHOD INCLUDE:}

Conveying the applicability of the project, especially at the outset

'You can't learn about childhood development from a visit to one child.'

To succeed the Family Study needs to connect with a variety of other areas of the curriculum. As the visits proceed and findings are drawn into other classes, this becomes more achievable, but until these connections are clear students express difficulty in seeing the benefits 
of the work. The duration of the project requires a degree of patience and faith on the part of the students that they are working towards concrete learning outcomes.

'A lot of the questions were inappropriate as our child was so young.'

The recruitment criteria that families only need include one child under five results in a diverse age range of children being included in a relatively small total sample. Designing questionnaires that can be administered by all the groups without compromising the integrity of the sample as a whole sample can be problematic. This is necessary to maintain for the research-orientated elements of the final project, and it does give students a practical insight into guaranteeing universal relevance in the design of data collection tools. It can also serve to highlight for students the mismatch between what academic study tells them about children's development, and what parents understand of their children, which is important in a profession where communications with children are so often mediated by parents. The most notable example of this relates to data collection on friendship groups: the family study questionnaire asks if the children have a particular best friend. Students with very young study children often object to the inclusion of this question as lectures on childhood development elsewhere in the course teach them that babies will not have formed such relationships. Yet in the Family Study parents of children as young as six months have claimed their children do have best friends, understanding them to be socially capable as 'friends' long before the theories of childhood development would suggest.

Organisational and logistical issues of recruitment and retention of participating families

Although evidence suggests that patients who participate in medical education are positive about the experience, ${ }^{11,12}$ recruitment can be difficult. In the Family Study, recruitment is dependent on the co-operation of third parties and can therefore be unpredictable. Low or slow recruitment has at times required students to work in groups of three rather than pairs, and the rescheduling of some visits. Parents being absent at prearranged appointments has been a small but recurrent issue. Drop out rates of participating families due to geographical mobility have been as high as $30 \%$ in any one year. In these circumstances, students visit replacement families but cannot therefore follow individual progress.

'The previous meeting was missed as the mother had forgotten that she had arranged to meet us.'

'Our original family moved away from the area so we could not follow the child's progress as intended.'

Reducing the time gap between visits would reduce the attrition rate to some degree, but doing so would risk reducing the changes that the students observe over time, which especially in the case of children in infancy at the first visit, can be significant and are often an enjoyable aspect of the visits for the students.

\section{DISCUSSION}

The Family Study encourages students to think about families and interactions in different ways to those usual to their training. The project roots behavioural sciences teaching in direct and applied environments, away from clinical settings, and helps support a more holistic and integrated approach to learning and patient care. It does carry a high academic and administrative load to implement, and a commitment to a continuing, consistent and connected curriculum component which will develop student skills but not yield assessment outcomes until some years after its initiation. In a climate of continual feedback and assessment, such a strategy can be problematic and at times dissatisfying for students, despite attempts to feed back family study data and issues in other areas of the curriculum. Yet ultimately the Family Study represents an innovative method of delivering and supporting behavioural sciences teaching in dental education, offering opportunities to apply findings across a range of subject areas including communications skills, public health, sociology, child development and research methods.

It is perhaps appropriate to close with this reflection written by a Year 4 student in their final project report, looking back on their initial view of the project and how this had changed by its completion. It illustrates concisely the purpose and learning journey this curriculum component strives to achieve:

'Without trying to antagonise or annoy the person who set this project, it is sometimes difficult to understand how this project will improve me as a dentist. Before this paper is thrown in the bin I must stress that these were only my initial thoughts. There is very little association between the family study and the actual work done by a dentist when carrying out a treatment plan, and I think this is the first area of the study that should be modified. Questions should be added such as: do you know what fissure sealants are? If so, what are your opinions on fissure sealants? If the first answer is no, then the student could inform the parents what they are and the parents could then make an informed decision on whether they want them for their child or not. Similar questions could be asked on oral hygiene instruction and many other comparable topics.

'After realising there is much more to dentistry then drilling and filling teeth it became clearer as to why we were assigned this project. The family study gave me the first opportunity to come into contact with the general public as part of a profession. My interview technique must have improved and will help me during the final year project and any further journal studies that may require questionnaire work. It also allowed me to assess the development of a child as a whole, rather than just the development of their dentition. I picked up useful tips as to when children start to develop certain social skills like imitating people and when they learn how to respond to praise and encouragement. All these bits of information will hopefully provide me with a greater chance of treating paediatric patients successfully.'

Such a journey, when achieved, helps achieve the aims set out for behavioural sciences in The first five years, broadening the experiences of students from mostly traditional science backgrounds, strengthening their understanding of social issues, and integrating communications skills learning from the start of their training. As such, family outreach programmes such as the Family Study offer a valuable addition to behavioural science curricula. 
1. General Dental Council. The first five years: the undergraduate dental curriculum. London: GDC, 1997.

2. General Medical Council. Tomorrow's doctors London: GDC, 1993.

3. Spencer J A, Jordan R K. Learner centred approaches in medical education. Br Med J 1999; 318: $1280-1283$

4. Forster D P, Drinkwater C K, Corradine A et al. The family study: a model for integrating the individual and community perspective in medical education. Med Educ 1992; 26: 110-115.
5. Pill R M, Tapper-Jones L M. An unwelcome visitor? The opinions of mothers involved in a communitybased undergraduate teaching project. Med Educ 1993; 27: 238-244.

6. Henley L D. A home visit programme to teach medical students about children with special needs. Med Educ 1999; 33: 749-752.

7. Howe $A$, Ives $G$. Does community-based experience alter career preference? New evidence from a prospective longitudinal cohort study of undergraduate medical students. Med Educ 2001; 35: 391-397.

8. Elkind A. Outreach teaching: is this the future for dental education? Br Dent J 2002; 193: 111-112.

9. Blinkhorn FA. Evaluation of an undergraduate community-based course in Family Dentistry. Eur J Dent Educ 2002; 6: 40-44.

10. Mossey P. The changing face of dental education. Br Dent J 2004; Education supplement: 3-4.

11. Howe A, Anderson J. Involving patients in medical education. Br Med J 2003; 327: 326-328.

12. Stacy R, Spencer J. Patients as teachers: a qualitative study of patients' views on their role in a community-based undergraduate project. Med Educ 1999; 33: 688-694. 